\title{
Cavernous Malformation of the Optic Chiasm with Multiples Cerebral Cavernous Malformations
}

\author{
M Mbaye $^{1 *}$, M Thioub ${ }^{1}$, C Popa ${ }^{2}$, F Signorelli ${ }^{2}$ and I Pelissou-Guyotat ${ }^{2}$ \\ ${ }^{1}$ Neurosurgery unit, Fann National University Hospital, Dakar \\ ${ }^{2}$ Neurosurgery D, Pierre Wertheimer Hospital, Lyon \\ *Corresponding author: M Mbaye, Neurosurgery unit, Fann National University Hospital, Dakar \\ Submission: September 20, 2017: Published: November 13, 2017
}

\begin{abstract}
Optochiasmal cavernous malformations are a most uncommon location of Cerebral Cavernous Malformations (CCMs). This rare lesion often presenting with headaches, acute or progressive visuals disturbances, or chiasmatic apoplexy. We reported a case of Cavernous Malformation (CM) of the optic chiasm who performed a total gross resection with a subfrontal approach. The clinical, radiological and intraoperative findings are presented and also a review of the literature.
\end{abstract}

Keywords: Cavernous malformation; Optic nerve; Optic chiasm; Surgery

\section{Introduction}

The cerebral cavernous malformations (CCMs) represent 10 to $20 \%$ of all vascular malformations with an incidence of 0.3 to $0.7 \%$ in the general public [1]. Cavernous malformations (CMs) originating from cranial nerves have rarely been reported. Cranial nerves such as the optic nerve and chiasm, oculomotor, trigeminal, intracranial portion of the seventh and eighth nerve and hypoglossal nerve have been affected. The opto-chiasmatic location of cavernous malformation is extremely rare [2]. Clinical manifestations are dominated by visual disturbances and/ or chiasmatic apoplexy. We reported a rare case of opto-chiasmatic cavernoma in a context of cerebral cavernous malformations.
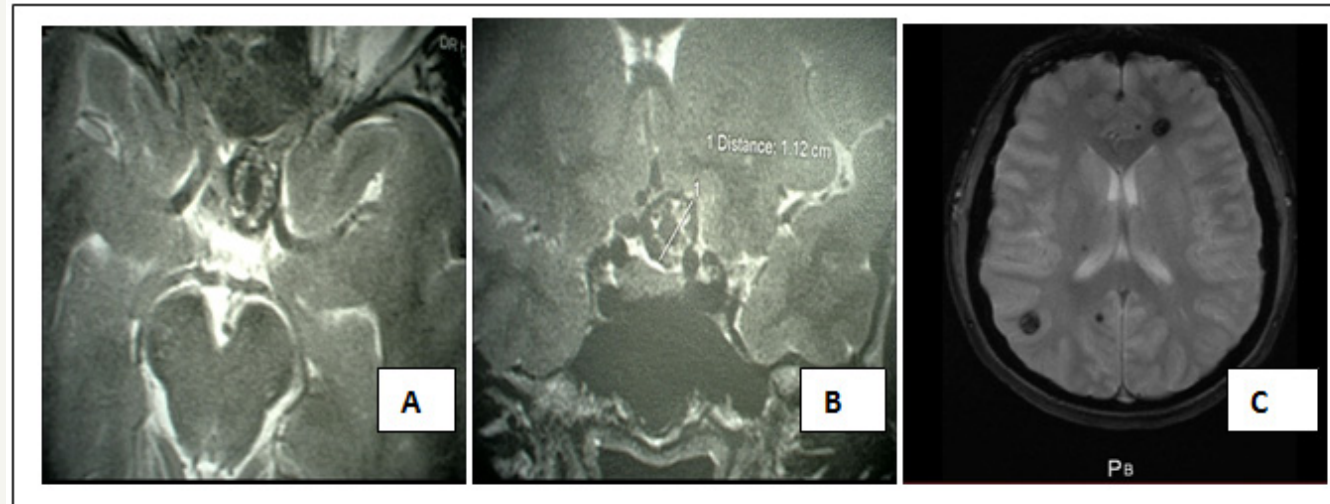

Figure 1: axial (A) and coronal (B) T2- weighted magnetic resonance images finds a cavernoma located in the left opto-chiasmatic cistern. Axial T2* (gradient echo) MRI(C) shows multiple cavernous malformations.

\section{Observation}

A 38-year-old female patient with a history of hypertension had visual blurring associated with headaches that had been progressing for a year. An ophthalmologic examination found a left pre-chiasmatic retrobulbar neuropathy with visual evoked potentials and visual acuity 10/10 in the left eye and right eye, a scotoma in the internal upper quadrant of the left eye, without ocular fundus abnormalities. Magnetic resonance imaging (MRI) revealed multiple cerebral cavernous malformations (CCMs), including one in the suprasellar region, a left frontal location, a right parietal and temporal location (Figure 1) and cerebral arteriography showed no cerebral malformation. The endocrinological assessment 
was normal. A definitive surgery of the symptomatic cavernoma was performed through a left sub-frontal approach and found a cavernous lesion at the left optic nerve junction and optic chiasm
(Figure 2). The removal was complete and after surgery there was a visual aggravation with a visual acuity of the left eye from $1 / 20$ with parinaud 10 in nasal at day 6 postoperative.

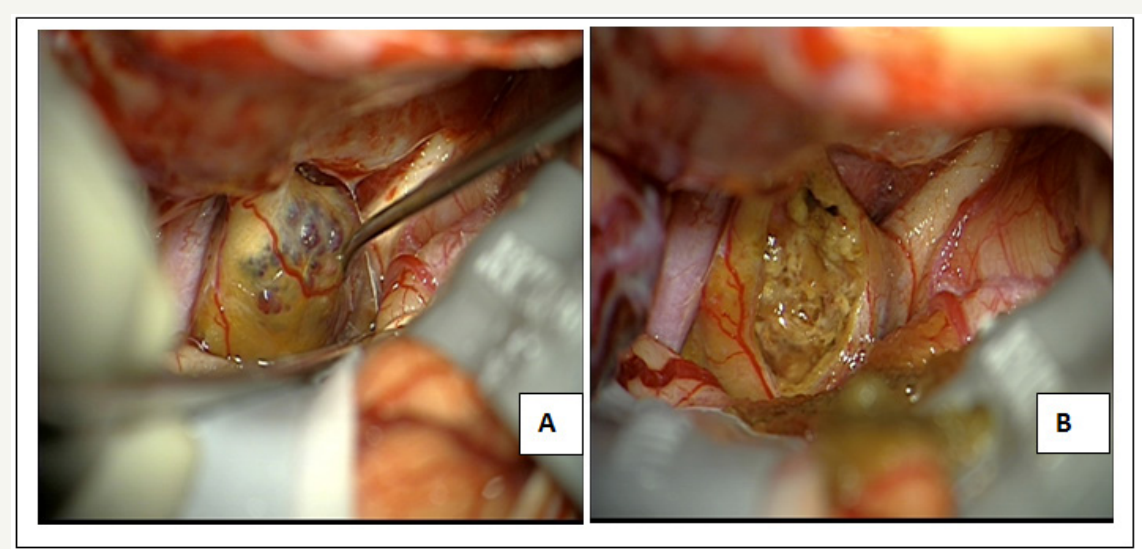

Figure 2: Surgical view.

A: Intraoperative aspect: a left subfrontal approach showed a cavernoma located in the left optic nerve and the chiasm, the right optic nerve and the left internal carotid artery are also visualized;

B: Aspect at the end of the intervention with a gross total resection.

An ophthalmologic examination at 6 months showed that the scotoma was persisting and the left eye visual acuity remained unchanged. A histological analysis had confirmed the diagnosis of cavernoma and a MRI at 3 months showed no suprasellar cavernous malformation (Figure 3).

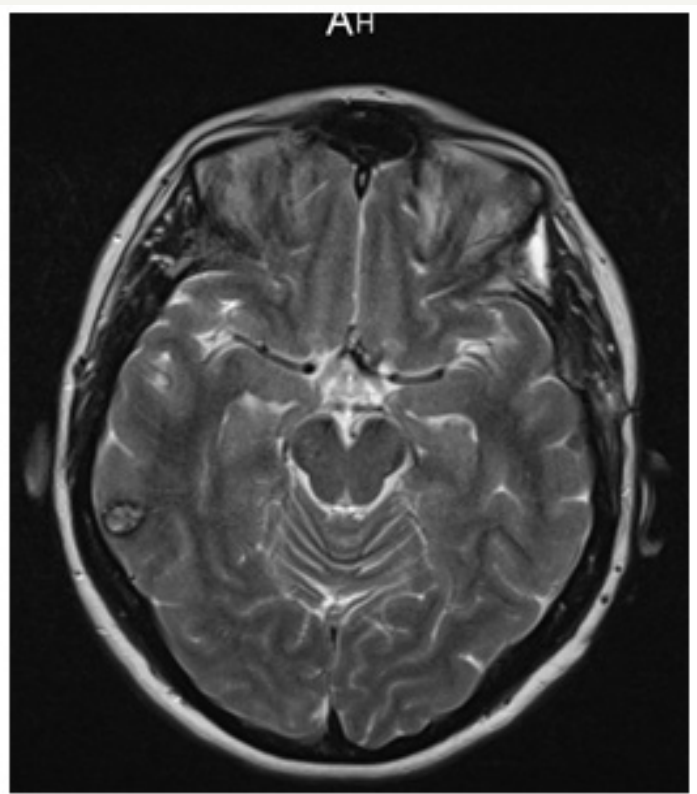

Figure 3: Post-operative MRI T2- weighted, 3 months after surgery showed complete resection of the optic chiasm cavernous malformation.

\section{Discussion}

The CCMs are histologically benign lesions composed of sinusoidal capillaries. The opto-chiasmatic location is rare and the risk of visual aggravation by bleeding constitutes the danger of this location. Their surgical management is also a challenge. Association with cerebral cavernous malformations is exceptional. Currently about 80 cases of optochiasmatic cavernomas have been reported in the international literature since the first description in 1958 [3]. CCMs are sporadic in 50-80\%; patients with familial forms constitute $8-19 \%$ and usually present multiple CCMs [3,4].

The annual bleeding risk of cavernomas is $0.6 \%$ / year and $4.5 \% /$ year of re-bleeding [5]. The functional impotence of this region explains the presence of clinical signs at the slightest bleeding. In our case the malformation bleed and this motivated surgical removal.

Clinical manifestations are usually represented by a sharp or progressive decrease in visual acuity with or without amputation of the visual field associated with headaches; retro-orbital pains sometimes even involvement of other cranial nerves or a subarachnoid hemorrhage, and even chiasmatic apoplexy. A systematic review of the analysis of 65 cases of the literature found the predominance of the decrease in visual acuity in $98 \%$ of the patients, and had found in $60 \%$ of the cases retro-orbital pains or headaches and $58 \%$ of cases of chiasmatic apoplexy.

A review of the literature reveals a clear predominance of the female sex (59\%) with an average age of discovery between 20-40 years. In this location a genetic diagnosis can find an associated genetic mutation such as KRIT1/ CCM1 in 7q, CCM2 in 7qn PDCD10/ CCM3 in 3q [3,6]. Differential diagnosis is made with other lesions such as optic nerve glioma, haemangioblastoma in the context of Von Hippel Lindau's disease, craniopharyngioma, pituitary adenoma, trombosed aneurysm, multiple sclerosis or optic neuritis [7]. The radiological assessment often finds recent or chronic bleeding and sometimes calcifications. The association with cerebral cavernomatosis is found in $15 \%$ of cases. Cerebral arteriography is negative and MRI finds a lesion of the heterogeneous 
suprasellar region with a "popcorn like" aspect in iso T1 signal and hyper T2 signal, the T2-weighted gradient echo sequence (T2*) allows to confirm the vascular nature of the lesion in the form of a marked hypo signal. Contrast enhancement is usually minimal after injection of gadolinium. Type I CCMs appear homogeneously hyperintense on $\mathrm{T} 1$ images due to methemoglobine predominance in subacute hemorrhage. Type II CCMs are heterogeneous on both $\mathrm{T} 1$ and T2 sequences, showing a reticulated mixed signal core ("popcorn"). Type III CCMs are hypointense to isointense on T1 images, hypointense on T2 images, and markedly hypointense on T2* images due to hemosiderin predominance. Type IV CCMs show tiny, punctate foci that are hypointense on T1 and T2 images, often multiple, and best seen on $\mathrm{T} 2 *$ images $[8,9]$.

Surgical management is widely adopted in most cases reported in the literature. It is $97 \%$ in the review of Liu et al. [2] it consists of a total gross resection in $60 \%$ of the cases. The preferred surgical approach is an anterolateral approach (pterional, orbitozygomatic, or frontotemporal) was used in $76 \%$ of patients, and a midline transcranial approach (transbasal subfrontal or transbasal interhemispheric) in $17 \%$. Postoperative findings showed an improvement in VA in $73.4 \%$ of cases and an aggravation of $05.3 \%$ [10].

The surgical indication is motivated by the neurological deficit and allows the definitive diagnosis. Evolution without any treatment can occur towards vision loss due to iterative bleeding within the lesion [11].

\section{Conclusion}

Our patient presented with exclusive visual symptoms, despite the presence of other location of cerebral cavernous malformation. The association of this location with a cerebral cavernous malformation is rare. For CCMs in any location in the neuraxis, MRI is the method of choice for diagnosis, classification, and followup. Surgical removal is the recommended treatment to restore or preserve vision, to eliminate the risk of future hemorrhages for symptomatic and accessible lesions.

\section{References}

1. Moriarity JL, Clatterbuck RE, Rigamonti D (1999) The natural history of cavernous malformations. Neurosurg Clin N Am 10(3): 411-417.

2. Liu JK, Lu Y, Raslan AM, Humayun Gultekin S, Delashaw JB (2010) Cavernous malformations of the optic pathway and hypothalamus: analysis of 65 cases in the literature. Neurosurg Focus 29(3): E17.

3. Del Curling O, Kelly DL, Elaster AD, Craven TE (1991) An analysis of the natural history of cavernous angiomas. J Neurosurg 75(5): 702-708.

4. Deshmukh VR, Albuquerque FC, Zabramski JM, Spetzler RF (2003) Surgical management of cavernous malformations involving the cranial nerves. Neurosurgery 53(2): 352-357.

5. Uihlein A, Rucker CW (1958) The Neurosurgeon's role in acute visual failure. Arch Ophathalmol 60(2): 223-229.

6. Iwai Y, Yamanaka K, Nakajima H, Miyaura T (1999) Cavernous angioma of the optic chiasm--case report. Neurol Med Chir 39(8): 617-620.

7. Cerase A, Franceschini R, Battistini S, Vallone IM, Penco S, et al. (2010) Cavernous Malformation of the Optic Nerve Mimicking Optic Neuritis. J Neuroophthalmol 30(2): 126-131.

8. Zabramski JM, Wascher TM, Spetzler RF, Johnson B, Golfinos J, et al. (1994) The natural history of familial cavernous malformations: results of an ongoing study. J Neurosurg 80(3): 422-432.

9. Raychaudhuri R, Batjer HH, Awad IA (2005) Intracranial cavernous angioma: a practical review of clinical and biological aspects. Surg Neurol 63(4): 319-328.

10. Son DW, Lee SW, Choi CH (2008) Cavernous Malformation of the Optic Chiasm: Case Report. J Korean Neurosurg Soc 44(2): 88-90.

11. Hempelmann RG, Mater E, Schroder F, Schon R (2007) Complete resection of a cavernous haemangioma of the optic nerve, the chiasm and the optic tract. Acta Neurochir 149(7): 699-703. 